Culture et histoire dans l'espace roman

4 | 2010

Les représentations du corps dans la litterature latinoaméricaine

\title{
Los tajos del « cuerpo deseante » en Loco afán Crónicas de sidario de Pedro Lemebel
}

\section{Henri Billard}

\section{(2) OpenEdition}

\section{Journals}

Edición electrónica

URL: https://journals.openedition.org/cher/8662

DOI: $10.4000 /$ cher.8662

ISSN: 2803-5992

\section{Editor}

Presses universitaires de Strasbourg

\section{Edición impresa}

Fecha de publicación: 30 junio 2010

Paginación: 39-48

ISBN: 978-2-35410-007-0

ISSN: 1968-035X

\section{Referencia electrónica}

Henri Billard, «Los tajos del « cuerpo deseante » en Loco afán Crónicas de sidario de Pedro Lemebel», reCHERches [En línea], 4 | 2010, Publicado el 15 diciembre 2021, consultado el 24 enero 2022. URL: http://journals.openedition.org/cher/8662 ; DOI: https://doi.org/10.4000/cher.8662

\section{(c) (†) ()}

Ce(tte) œuvre est mise à disposition selon les termes de la Licence Creative Commons Attribution -

Pas d'Utilisation Commerciale - Partage dans les Mêmes Conditions 4.0 International. 


\title{
Los tajos del "cuerpo deseante » en Loco afán Crónicas de sidario de Pedro Lemebel
}

\author{
HENRI BILLARD \\ Université de Poitiers
}

Ca irrupción de las dictaduras, como la de Argentina y en menor medida las sociedades latinoamericanas que venía dándose desde finales de los años sesenta. Este proceso se vio gatillado por la influencia de la revuelta parisina de mayo del 68, la primavera de Praga, los movimientos por los derechos civiles en Estados Unidos, el feminismo, el rock, el hippismo y el pacifismo, en respuesta a la guerra de Vietnam. El máximo apogeo de esta ola liberalizadora se vivió en Chile durante los mil días del gobierno de Salvador Allende. Con su caída, se derrumbaron las aspiraciones tanto para un sector de la clase politica y de la población como para las minorías sexuales. Cabe recordar que la primera manifestación pública por los derechos de los homosexuales en Chile tuvo lugar precisamente durante el gobierno de Salvador Allende, el 22 de abril de 1973. Lo que no quiere decir que este gobierno fuera favorable a este movimiento. Sin embargo, el solo hecho de que la manifestación pudiera realizarse testimonia del ambiente de libertad que existía en aquella época. Tras el triunfo del golpe organizado por los altos mandos de las Fuerzas Armadas chilenas el 11 de septiembre de 1973, se instauró una época de represión en todos los ámbitos al igual que en otros países del subcontinente.

A finales de los años setenta, justo antes de la aparición del sida, una nueva corriente libertaria llegaba desde los sectores más liberales y organizados de los Estados Unidos. La elección de Harvey Milk, defensor abiertamente gay de los derechos de los homosexuales, como consejero municipal de 
la ciudad de San Franciso en 1977 fue uno de los hitos de esta época de cambios en la sociedad estadounidense. Gracias a ella se experimentó un nuevo resurgimiento de la vida gay latinoamericana, sin alcanzar, claro está, la visibilidad de los locales para esparcimiento gay existentes en ciudades como Nueva York y San Francisco. Poco a poco, los ecos de las libertades alcanzadas en el mundo industrializado fueron mermando el conservaturismo impuesto por la derecha más tradicional y los militares, tanto en Argentina como en Chile y Uruguay entre otros. Por ejemplo, hacia fines de 1977, se «fundó el grupo Integración, la primera organización gay durante la dictadura de Pinochet» (Robles 2008: 19), según los testimonios recogidos por Victor Hugo Robles en su libro Bandera Hueca, y en 1979, abría sus puertas, discretamente, la primera disco gay chilena.

Estando Argentina en dictadura encontramos en 1967 a "Nuestro Mundo", uno de los primero grupos por los derechos de las minorías sexuales de América Latina. Más tarde, en 1971, esta asociación se unió a otras diez organizaciones para dar origen al "Frente de Liberación Homosexual" (FLH). De este movimiento surgió la idea de crear en 1973 Somos, la primera revista en que se incluían contenidos abiertamente gays en América Latina, cuya circulación se detuvo sólo dos meses antes del golpe de 1976. En Buenos Aires, luego de la restauración democrática, «el 16 de abril de 1984, en la disco Contramano, de Rodríguez Peña casi Santa Fe, cerca de 150 personas dieron nacimiento a la Comunidad Homosexual Argentina» (Bazán 2004: 397), retomando así espíritu de los primeros movimientos por los derechos de las minorías sexuales.

Esta onda de cambio y de apertura sufrirá un golpe devastador con la aparición del llamado "cáncer gay". En el año 1981 se conocerán los primeros casos del síndrome de inmunodeficiencia adquirida o sida. Con él nacerá una época que marcará un antes y un después para los hombres y mujeres homosexuales. En un principio los medios de comunicación no daban demasiada cobertura al tema, a tal punto que se puede afirmar que fueron los efectos de la muerte de Rock Hudson en 1985 y la revelación de su homosexualidad, los que dieron un impulso mediático definitivo a la enfermedad. Cabe recordar además, que en un principio las asociaciones por los derechos de los gays y lesbianas se negaban a aceptar las conclusiones de los científicos. Se temía entonces que la enfermedad hiciera resurgir la discriminación y los prejuicios asociados a la homosexualidad. De hecho, hasta finales de la década de los ochenta (Broqua y Fillieule 2003: 430), las asociaciones de lucha contra el sida hacían todo lo posible por evitar la 
amalgama entre sida y homosexualidad. Todavía no había una conciencia clara de las implicancias del sida. A lo más era la enfermedad del "otro". Finalmente será el duelo asociado a la muerte de una pareja o de amigos lo que favorecerá la emergencia de una estrategia común para hacer frente a la enfermedad.

A nivel literario, el sida atrajo el interés de numerosos escritores abiertamente homosexuales o sensibles a la imaginería homosexual. En la mayoría de los relatos que abordan el sida como temática, encontramos un cuestionamiento interior motivado por el dolor y el miedo, junto a una gran nostalgia por una época en la que no había restricciones para la sexualidad entre dos hombres. El fenómeno se ha dado tanto en los Estados Unidos como en Europa y en América Latina. Gran repercusión han tenido, por ejemplo, las novelas Les nuits fauves de Cyril Collard y A l'ami qui ne m'a pas sauvé la vie de Hervé Guibert. Ambos autores nacen a fines de los años cincuenta; vale decir, a ellos les tocó vivir su madurez sexual en medio del estigma y la marginalización que el sida trajo a los homosexuales. Entre otros autores, cabe mencionar también al escritor estadounidense David Leavitt, nacido en 1961, quien pone precisamente en evidencia el cambio en las prácticas sexuales de los homosexuales en El lenguaje perdido de las gruas (The lost language of cranes), publicada en Nueva York en 1986. Esta novela marcará además a toda una generación por haber tratado con "naturalidad" temas tan sensibles como la salida del clóset de un hijo y la doble vida de un padre que nunca ha asumido su homosexualidad.

En América Latina, la novela autobiográfica Antes que anochezca (1990) de Reynaldo Arenas alcanzará una gran notoriedad internacional por su desgarrador relato de la realidad cubana, así como de la experiencia de vivir siendo seropositivo. Otro nombre que merece ser citado es el de Nestor Perlongher porque como lo destaca Gabriel Giorgi: «[e]n Perlongher, el sida vuelve explícito y definitivo ese lugar de la homosexualidad como cuerpo terminal, como materia del fin, que se encarna en diferentes escenas y contextos en la loca y sus destinos» (Giorgi 2004: 154). También podemos mencionar al autor peruano-mexicano Mario Bellatin y su relato breve Salón de belleza ${ }^{1}$ (1994), al escritor argentino Pablo Pérez por su novela Un año

1 Según Mario Bellatin la novela Salón de belleza tiene como punto de partida un hecho real que apareció en la prensa peruana: «[p]artí de una noticia que encontré en un diario. Allí decía que había un peluquero que recogía enfermos de sida en un barrio marginal de Lima. Esta anécdota me pareció que podía ofrecer un espacio rico para crear. A partir de ese momento ingresó mi propia invención». Ver Jorge Coaguila, «Deseo la ambigüedad... ", La República, Lima, 1 de enero de 1995, p. 25-26. 
sin amor. Diario del sida (1998) y a Fernando Vallejo por El desbarrancadero (2001). E, igualmente, resulta imposible no referirse al escritor chileno Pedro Lemebel. Sus crónicas, sus legendarias intervenciones tanto en la radio como en la televisión y los medios de prensa escrita refiriéndose al sida, a la hipocresía masculina, a la dictadura de Pinochet y a las contradicciones de la clase política chilena, han hecho de él una voz disonante en el "nuevo" Chile. Una "lengua salada" (Lemebel 2008: 11) en un país que "blanqueó" a Pinochet, como nos lo recuerda Tomás Moulian, para «conseguir que los agentes económicos mantuvieran su confianza» (Moulian 2002: 45) porque el nuevo gobierno que iba a suceder a Pinochet, encabezado por el líder de una coalición de centro izquierda, Patricio Aylwin, tenía como objetivo prolongar, aunque con matices, el modelo socioeconómico heredado de la dictadura.

Por medio de sus crónicas, Lemebel da voz al margen, a la llamada "loca", en su representación más extrema: el travesti homosexual. El lenguaje de esta voz es una performance hecha de metáforas, imágenes y alusiones. Al igual que el cuerpo de la "loca", que con su presencia denuncia «la discontinuidad radical entre el sexo del cuerpo y los géneros culturalmente construidos» (Butler 2006: 67), la escritura de Lemebel "es y no es", se transforma, se trasviste y, por ende, perturba. Se trata de la «escritura vivencial de [un] cuerpo deseante» (Lemebel 2000: 88) ${ }^{2}$, un cuerpo "nacional", que denuncia y critica dos flagelos: el sida y la dictadura, haciendo visible lo que no se quiere ver. A través de sus crónicas, Lemebel escribe una historia "efectiva" que nos permite "conocer" para "saber" en el sentido dado por Foucault; es decir, no para comprender sino "para hacer tajos» ${ }^{3}$ (Foucault 1991: 20). Siguiendo entonces a Foucault, intentaremos demostrar cómo Lemebel se opone a la historiografía tradicional, por medio de una escritura que intenta hacer resurgir el suceso a través de una mirada dispersa sobre el cuerpo subversivo de la "loca".

El nombre de Pedro Lemebel comienza a adquirir notoriedad pública en Chile en los años ochenta, gracias a polémica y el escándalo que suscitaron sus primeras apariciones públicas. Entre las que más han marcado la historia

2 «La flama busquilla de la marica relampaguea siempre en presente y equivoca su captura en el espejo cambiante de su sombra. La ciudad se lo perdona, la ciudad se lo permite, la ciudad la resbala en el taconeo suelto que pifia la identidad con la errancia de su crónica rosa. Una escritura vivencial del cuerpo deseante, que en su oleaje temperado palpa, roza y esquiva los gestos sedentarios en los ríos de la urbe que no van a ningún mar».

3 La cita completa dice: «el saber no ha sido hecho para comprender, ha sido hecho para hacer tajos ». 
cultural chilena reciente, podemos mencionar las expresiones artísticas del colectivo formado por Fernando Casas y Pedro Lemebel, Las yeguas del Apocalípsis, y la lectura de su Manifiesto (Hablo por mi diferencia) en septiembre de 1986, durante una reunión de los partidos de izquierda en la Estación Mapocho de Santiago. En aquella oportunidad, el autor, que fue un duro opositor a la dictadura de Pinochet, interpeló con su manifiesto a la izquierda por su actitud con los homosexuales. Pero no sólo la izquierda chilena es blanco de la reprobación ejercida por el discurso de Lemebel. La crítica ácida y certera de la pluma lemebeliana irá también hacia la realidad cubana, asumiendo de paso la voz de los que han sido marginados debido a su orientación sexual. Así, el autor interpela a sus compañeros de izquierda con la agudeza crítica que lo caracteriza: «¿Y entonces? ¿Qué harán con nosotros compañeros? / ¿Nos amarrarán de las trenzas en fardos con destino a un sidario cubano?» (Lemebel 1997: 84).

La performance, el video y las instalaciones irán conduciendo progresivamente a Lemebel hacia la crónica. Experiencias político-culturales ${ }^{4}$ como la realizada en la sede de la Comisión Chilena de Derechos Humanos el 12 de octubre de 1989, es un excelente ejemplo. Por aquel entonces, Las yeguas del Apocalípsis bailaron un pie de cueca, descalzos, sobre un mapa de América Latina cubierto con diez botellas trizadas de Coca-Cola hasta cubrirlo de rojo fruto de las auto-flagelaciones. Esta forma de (re)escribir la historia con la sangre homosexual, buscando denunciar las desapariciones de homosexuales y políticos durante la dictadura, ilumina el "suceso crudo" por medio de la performance para luego retomarlo por medio de la escritura. En este sentido, la pluma lemebeliana establece «una relación de fuerzas que se invierte» (Foucault 1991: 21), permitiendo que las palabras se liberen, desnudando de paso los artificios de la verdad "oficial”.

En las crónicas de Pedro Lemebel predomina entonces la primera persona del singular, siendo a la vez narrador y en muchos casos protagonista o testigo de lo narrado. Además, encontramos de manera recurrente el registro oral de personajes marginales, "espectros" que no tienen cabida en el Chile posdictatorial. Un Chile que se ha "trasvestido" en un país que se considera exitoso y a un paso de alcanzar el primer mundo, que se niega a ver la desigualdad social que trajo la aplicación del modelo neoliberal y las heridas que la dictatura dejó en la sociedad chilena. Un país con una fuerte

4 Ver http://www.memoriachilena.cl/archivos2/pdfs/MC0044728.pdf 
«compulsión al olvido» (Moulian 2002: 31) como bien lo señala Tomás Moulian en su libro Chile Actual: Anatomía de un Mito.

El tema de la historia "efectiva" en oposición a la "sábana blanca" (Blanco y Gelpi 2004: 152) de la amnesia chilena, servirá entonces de hilo conductor a las crónicas de Pedro Lemebel. El autor deconstruye la historia "oficial" para hacer «resurgir el suceso en lo que puede tener de único, de cortante» (Foucault 1991: 21) a través de la "politización" del cuerpo de la loca. En Loco afán. Crónicas de sidario, por ejemplo, encontramos un provocador cruce entre el sida, la homosexualidad marginal de los travestis y la historia política de Chile desde los últimos meses del gobierno de Salvador Allende hasta el primer gobierno posdictadura (1972-1992). En una de las crónicas de Loco afán, llamada "La noche de los visones (o la última fiesta de la Unidad Popular», nos encontramos con una fiesta de año nuevo que va desde el atardecer del 31 de diciembre de 1972 hasta la llegada del fatídico 1973.

A esa gran comilona que había prometido la Palma, esa loca rota que tiene puesto de pollos en la Vega, que quiere pasar por regia e invitó a todo Santiago a su fiesta de fin de año. Y dijo que iba a matar veinte pavos para que las locas se hartaran y no salieran pelando. Porque ella estaba contenta con Allende y la Unidad Popular, decía que las pobres iban a comer pavo ese año nuevo. Y por eso corrió la bola que su fiesta sería inolvidable (Lemebel 1997: 12).

Las "locas regias", la Astaburuaga, la Zañartu y la Pilola Alessandri también fueron a la fiesta. La "anfitriona" no esperaba a tan ilustres visitas y menos aún que llegaran con visones en pleno verano. Pero ahí estaban los visones de la madre de la Pilola, uno negro y el otro blanco, «como la Taylor, como la Dietrich»(13), en ese barrio popular y «las viejas pobladoras no lo podían creer» (13) al verlas entrar «empieladas» (13) a la casa de la Palma. Por medio de esta estrategia de escritura que pone de relieve los opuestos regias-rotas, blanco-negro, etc, Lemebel anuncia el fin de la esperanza asociada al gobierno de Allende y al mismo tiempo la llegada de la dictadura. Como la Palma, Allende también había invitado a todo el mundo, sin distinción de clases, para construir un nuevo Chile, pero la utopía estalló en pedazos y con ella, los sueños de una generación.

La descripción detallada de transformación de los restos de los pavos de la fiesta será también una premonición de la sombra mortuoria que cubrirá al país a través de la represión de los militares y más tarde con la epidemia del sida. 
Por todos lados, las locas juntaban huesos y los iban arreglando en la mesa como una gran pirámide, como una fosa común que iluminaron con velas. Nadie supo de dónde una diabla sacó una banderita chilena que puso en el vértice de la siniestra escultura. [...] Como si el huesario velado, erigido aún en medio de la mesa, fuera el altar de un devenir futuro, un pronóstico, un horóscopo anual que pestañeaba lágrimas negras en la cera de las velas, a punto de apagarse, a punto de extinguir la última chispa social en la banderita de papel que coronaba la escena (Lemebel 1997: 12-13).

Esta escultura posmoderna anuncia el «tufo mortuorio de la dictadura» (16) que a la vez era un adelanto macabro de la irrupción devastadora del sida. En efecto, con la llegada del golpe del 11 de septiembre, una «nevazón de balas provocó la estampida de las locas» (15) aunque "[s]iguieron las fiestas, más privadas, más silenciosas, con menos gente educada por la cripta del toque de queda»(15). La fiesta privada nocturna, entre el comienzo y el levantamiento del toque de queda, era uno de los pocos medios de socialización de que disponían los homosexuales de esa época. Hombres y mujeres homosexuales buscaban relacionarse entre sí, estableciendo una zona de seguridad que los apartara y protegiera. El hecho de estar juntos daba una sensación de estar a salvo de la marginación que implicaba la mirada y el rechazo del mundo exterior. En la fiesta, la celebración de la vida alcanzaba su plenitud.

Risas, miradas de deseo y libertad eran los ingredientes superficiales de estos espacios nocturnos. Si se escarba tan solo un poco, bajo esta burbujeante superficie yace un hondo anhelo de intimidad, de comunión con un otro, de aceptación, de reciprocidad, de compartir la propia vulnerabilidad emocional, como lo recuerda con acierto el cronista al describir la única foto que queda de aquella última fiesta de la Unidad Popular.

De esta fiesta sólo existe una foto, un cartón deslavado donde reaparecen los rostros colizas lejanamente expuestos a la mirada presente. La foto no es buena, pero salta a la vista la militancia sexual del grupo que la compone. Enmarcados en la distancia, sus bocas son risas extinguidas, ecos de gestos congelados por el flash del último brindis. Frases, dichos, muecas y conchazos cuelgan del labio a punto de caer, a punto de soltar la ironía en el veneno de sus besos. La foto no es buena, está movida, pero la bruma del desenfoque aleja para siempre la estabilidad del recuerdo. La foto es borrosa, quizás porque el tul estropeado del SIDA, entela la doble desaparición de casi todas las locas (16). [...] Tal vez, la foto de la fiesta donde la Palma, es quizás el único vestigio de aquella época de utopías sociales, donde las locas entrevieron aleteos de su futura emancipación (Lemebel 1997: 21). 
El tono nostálgico del relato acentúa el poder evocador de este trozo de memoria. En él se articulan los ecos de luchas sociales con los derechos de las minorías sexuales y las consecuencias desastrosas del sida. El testimonio inanimado cobra una nueva vida por medio de la narración, haciendo resurgir el suceso singular, el instante atrapado que hace las veces de actor social y testigo de una utopía rota. La "militancia sexual del grupo" no tan solo pone en evidencia el carácter ficcional que vincula género con sexo, sino que además "politiza" el cuerpo enfermo de la loca para denunciar el uso que se hace del sida como arma moralizante de la sexualidad.

En Loco afán el sida es una invasión, una nueva colonización procedente de los Estados Unidos. Así, al conocer los detalles de la muerte de la Pilola Alessandri, el narrador nos señala que "[e]lla se compró la epidemia en Nueva York, fue la primera que la trajo en exclusiva, la más auténtica, la recién estrenada moda gay para morir» (16). Cabe entrever en esta frase una crítica implícita a la invasión cultural proveniente de los Estados Unidos y, de paso, una sanción implícita a la obsesión de muchas locas con la moda y los símbolos de estatus social. La "loca" de Pedro Lemebel al igual que la de Néstor Perlongher, «designa un personaje de las culturas homosexuales hispánicas que combina afeminamiento y "nomadismo sexual" [como contrafigura] del [hombre] "gay", que aparece como un resultado de las políticas de [...] normalización social en torno a la homosexualidad» (Giorgi 2004: 170).

El "hombre homosexual" o "mister gay", era una construcción de potencia narcisa que no cabía en el espejo desnutrido de nuestras locas. Esos cuerpos, esos músculos, esos bíceps que llegaban a veces por revistas extranjeras, eran un Olimpo de Primer Mundo, una clase educativa de gimnasia [...] Una nueva conquista de la imagen rubia que fue prendiendo en el arribismo malinche de las locas más viajadas, las regias que copiaron el modelito en New York y lo transportaron a este fin de mundo. Y junto al molde de Superman, precisamente en la aséptica envoltura de esa piel blanca, tan higiénica, tan perfumada por el embrujo capitalista (Lemebel 1997: 22-23).

Otro aspecto que favoreció la hegemonía del personaje gay es, sin duda, la propia aparición del sida, como bien lo ha observado Gabriel Giorgi: «El sida, por su parte, literaliza esta desaparición haciendo de la loca una víctima elegida, en la medida en que representa una sexualidad "no higiénica", no medicalizada, y desafiante [...]» (Giorgi 2004: 154). El modelo gay en cambio representa un cuerpo "ordenado", sano y a la vez cosmopolita que calza perfectamente con el proyecto modernizador del nuevo Chile. En cambio, la loca, con sus artificios, sus lentejuelas y sus pestañas a lo diva de 
Hollywood, molesta a los que buscan hacer de Chile un "modelo" y a la vez da sustancia a las reivindicaciones de las minorías sexuales.

Esta "recolonización a través de los fluidos corporales» (26) erradica a la loca del espacio cultural, para reemplazarla por el "mister gay", figura cosmopolita, sana, higiénica y políticamente correcta. De su mano viene también otra invasión, la del modelo neoliberal adoptado por la dictadura. Hay un reemplazo de la loca proletaria, auténtica y nacional por un "Superman, perfumado por el embrujo capitalista" que la transición democrática hará suyo. En Loco afán, crónicas de sidario, este reemplazo aparece retratado por medio del cruce entre el cortejo que acompaña el cadáver de la Chumilou, una de las locas pobres que participaron en la última fiesta de la Unidad Popular, con los manifestantes que festejan la victoria de los oponentes a la dictadura. En efecto, el relato hace coincidir la muerte de la Chumi con el día en que llegó la democracia a Chile tras la derrota que sufrió Pinochet el 5 de octubre de 1988.

Fue difícil atravesar esa multitud de jóvenes pintados, flameando las banderas del arcoiris, gritando, cantando eufóricos abrazando a las locas que acompañan el funeral de la Chumi. Y por un momento se confundió duelo con alegría, tristeza y carnaval. Como si la muerte hiciera un alto en su camino y se bajara de la carroza a bailar un último pie de cueca. Como si aún se escuchara la voz moribunda de la Chumi, cuando supo el triunfo de la elección (Lemebel 1997: 21).

Este "nuevo" Chile, el del arcoiris de la Concertación de Partidos por la Democracia, el de la transición y la vuelta a la vida republicana nacía de una negociación secreta entre la dictadura y el nuevo poder que tomará el mando el 11 de marzo de 1990. Se trata de una operación que Tomás Moulian llama, con indiscutible acierto, el "blanqueo" de Chile. La coincidencia entre la visión de Moulian y la de Lemebel es notable.

Esa estrategia se basaba, más que en el temor, en la complicidad con el proyecto. Pero tomaba el miedo - fantasma latente, atavismo de los hombres comunes - como justificación. Lo que en realidad se buscaba era resituar a Chile, construirlo como país confiable y válido, el Modelo, la Transición Perfecta. Para ello era necesaria la cirugía plástica, la operación transexual que convirtió al Dictador en el Patriarca (Moulian 2002: 39).

Esta cirugía plástica, necesaria a los ojos de la "elite decidora" para dar estabilidad al país y sobre todo prolongar el modelo neoliberal, no es más que un simulacro, una ilusión para engañar al ciudadano-cliente como lo hacen las mariposas de la noche que ejercen el "travestismo prostibular" (Lemebel 1997: 77): «El futuro amante embelesado, prefiere no pensar que 
bajo ese trapo hay una sorpresa, una cirugía artesanal del amarre [de los genitales masculinos], donde la transexualidad es otra ley de tránsito que desvía el rutinario destino del marido camino al hogar» (78). El cuerpo de la loca lemebeliana aparece entonces como un eco de la realidad chilena posdictadura. Una ilusión, una promesa incumplida que el cronista define como [e]l radiante amanecer democrático que llegó cargado de promesas para el Chile joven, y que luego, al correr de los años neoliberales, el "tanto tienes, tanto vales" de su oratoria, fue nublando el sol pendejo de la recién encielada libertad» (Lemebel 1997: 171).

\section{Bibliografía}

Bazán, Osvaldo, 2004, Historia de la homosexualidad en la Argentina, Buenos Aires, Marea.

Blanco, Fernando (ed.), 2004, Reinas de otro cielo. Modernidad y autoritarismo en la obra de Pedro Lemebel, Santiago, LOM.

Broqua, Cristophe y Fillieule, Olivier, «SIDA (les associations)», 2003, Dictionnaire des cultures Gays et Lesbiennes (sous la direction de Didier Eribon), Paris, Larousse.

Butler, Judith, (2006), Trouble dans le genre, La Découverte, Paris.

Foucault, Michel, (1991), Microfísica del poder, Madrid, La piqueta.

Giorgi, Gabriel, 2004, Sueños de exterminio. Homosexualidad y representación en la literatura argentina contemporánea, Rosario, Beatriz Viterbo.

Lemebel, Pedro, 1997, Loco afán, Santiago de Chile, LOM.

Lemebel, Pedro, 2000, «Homoeróticas urbanas» (o apuntes prófugos de un pétalo coliflor), Loco afán, Barcelona, Anagrama.

Lemebel, Pedro, 2008, Serenata cafiola, Santiago, Planeta-Seix Barral.

Moulian, Tomás, 2002, Chile Actual: Anatomía de un Mito, LOM, Santiago.

Robles, Víctor Hugo, 2008, Bandera Hueca: Historia del Movimiento Homosexual de Chile, Santiago, Arcis-Cuarto Propio. 